\title{
Efficient Contracts for Digital Content
}

\author{
Tobias Regner
}

CMPO and The University of Bristol

July 2004

\begin{abstract}
This paper analyses efficient contracts for digital content, focusing on the music industry. It contributes to the quest for an efficient intellectual property rights environment for information goods. Moreover, it adds an interesting application to the field of behavioural economics.

The model is set in a contract theory framework with the copyright holder being the principal and a consumer the agent. We offer three contract cases for analysis: strong copy protection, a strategically low price and voluntary reciprocal contributions.

Insights from the economics of information and behavioural economics -- information goods have public goods properties; social preferences are significant among individuals -- are applied to examine the value of a strict copyright enforcement in the digital age.
\end{abstract}

We find that endogenous incomplete contracts based on fair, reciprocal behaviour may achieve a firstbest allocation of information goods, while complete contracts are limited to second-best results.

Keywords: internet, music industry, social preferences, reciprocity, moral hazard, file sharing

JEL Classification: D82, H42, L82, L86

\section{Acknowledgements}

I thank the Leverhulme Trust for funding this research. I would also like to thank seminar audiences in Bristol, SERCI congress 2003 in Northampton, IPR workshop of HIIT in Helsinki and CESifo conference "Understanding the Digital Economy" in 2004. Moreover, I am grateful to Paul Belleflamme and Nick Feltovich for valuable discussions and to an anonymous referee for helpful comments.

\author{
Address for Correspondence \\ Department of Economics \\ University of Bristol \\ 12 Priory Road \\ Bristol \\ BS8 1TN \\ Tobias.Regner@bristol.ac.uk
}




\section{Introduction}

Copyright law originated in the 18th century ${ }^{1}$ and it is regar ded as an important cornerstone of successful intellectual property protection. However, recently it has been criticised strongly. Particularly its extensions to now over 100 years granted by U.S. Congress $\{$ and followed by other legislations $\{$ are widely seen as simply bad policy that misses out on the original intention of promoting the I progress of science and of useful arts" by granting a temporary monopoly.

Moreover, modern information and communication technology makes it increasingly di \pm cult to actually protect the copyright of a digital good. Illicit copies of music "les reach billions per year and there seems to be no way to st op the peer-to-peer -le trading with reasonable means.

Doubts about its appropriate design and its enforceability bring up the question whether copyright law is still an ad equate governance system for intellectual property rights in the digital age. A re there alternative ways of providing information goods, a more et cient eco-system for ideas than the one copyright law o eers? Modi ${ }^{-}$ed copyright structures ${ }^{2}$ give content creators more ${ }^{\circ}$ exibility compared to the strict copyright law. But why should content creat ors use them instead of strong protection of their rights, essentially giving up on something that has been granted to them by law?

O nce created, the reproduction (or copying) of a digital good does not cost any additional resources. Its distribution is also virtually costless. Therefore, marginal costs of digital goods are practically zero. They have public goods characteristics: they are non-rival and non-excludable.

However, Pareto-e \pm cient pricing according to $p=M C$ is not su \pm cient for rewarding artists for their work, so that at least their basic reservation costs are covered. Otherwise, there would be no motivation to create in the ${ }^{-}$rst place.

Social preferences based on fair and reciprocal behaviour might o Ber such an alternative. The " nancial reward for the artists is based on a su \pm ciently high number of fair-minded consumers who contribute voluntarily (if they enj oy the product). The "contract" between the artist and the consumers of his products relies on a trust-based relationship. In fact, fairness and reciprocity might be regarded as the enforcement device of a deliberately left open contract. Such voluntary contributions for infor mation goods can in fact be observed in reality. Takeyama (1994a) studies shareware software and R egner (2004) analyses the tipping behaviour in the Intern et service Google A nswers. It can be theoretically explained by social preferences models and numerous lab experiments generally con $^{-} \mathrm{rm}$ other-regarding behaviour. Fehr and Schmidt (2000), Charness and Rabin (2002) and Camerer (2003) give an overview of the literature.

We apply these two insights $\{$ information goods have public goods properties; social preferences are signi $i^{-}$cant among individuals $\{$to examine what type of contracts are e \pm cient in the digital age. Our tool of analysis is contract theory. Instead of the standard P rincipal-A gent-situation with a ${ }^{-} \mathrm{rm}$ and a worker

\footnotetext{
${ }^{1}$ It was ${ }^{-}$rst enacted in England with the statute of Anne (1709) and then in 1787 as part of the U.S. constitution.

${ }^{2}$ The Creative Commons license, for instance. See: www.creativecommons.org
} 
in the labour market, our model feat ures the copyright holder and consumers in information goods markets with uncertainty about the payment. We examine three di ierent cont ract scenarios under asymmetric information and analyse the respective private investment incentives and social welfare implications.

The goals of this paper are twofold. It aims to contribute to the quest for an e \pm cient intellectual property rights environment for information goods. We pursue this from a contract theory perspective. M oreover, we want to add an interest ing application to the ${ }^{-}$eld of behavioural economics.

O ur main - nding is that endogenous incomplete contracts may achieve a - rst-best allocation of information goods, while complete contracts are limited to second-best results. Moreover, any contract design can generate the highest pro ${ }^{-}$ts. Strong copy protection is not necessary for that.

O ur paper contributes to the literature on copyright. This strand of economic research started with the ${ }^{-}$rst formal analysis of copyright by Plant (1934) who in fact rejected the case for copyright mainly on the grounds of a su \pm cient ${ }^{-}$rst mover advantage to establish the product. Landes and Posner (1989) and Besen and Kirby (1989) are main papers with a general welfare approach. Other important works deal with speci ${ }^{-} \mathrm{c}$ aspects of copying. Liebowitz (1985) established the concept of indirect appropriability, Takeyama (1994b) analyses positive network e®ects from unauthorised copies and Varian (2000) examines the sharing of information goods. Watt (2000) o Bers an excellent survey of the literature as a whole.

We particularly consider the welfare eßects of copyright for digital content. O ne recent paper \{ Yoon (2002) \{ speci es the optimal level of copyright protection in the light of widespread digital copies. However, they do not take maintenance costs of the copyright system into account as we do. Varian (2004) analyses the problem of sharing as well, but he assumes a ${ }^{-}$xed number of consumers and homogeneous valuation of the product. Moreover, we consider the option of voluntary contributions, a relaxed copyright regime.

The rest of the paper is organised as follows. Section 2 explains the economic context of the paper. It gives a brief overview of the three strands of the economic theory we relate to: information economics, behavioural economics and contract theory. Section 3 sets up the basic model and derives the main results. We present some open aspects for future research and conclude in section 5 .

\section{Economic Context}

\subsection{Information Goods and Welfare Economics}

$M$ uch has been written about the New E conomy and the revolutionary e Rects of information technology on the economy. Much has also been put in perspective by serious accounts like Shapiro and Varian (1999), for example. However, one thing that indeed is about to change on the way to an informational society is 
the emergence of a number of goods $\left\{\right.$ digital information goods ${ }^{3}\{$ that rarely existed before. Computer software, digital music or electronic-books for instance are products of the informational society and their attribute of zero marginal costs of reproduction gives them public goods properties. ${ }^{4} \mathrm{~T}$ he use of one digital copy does not diminish the value of any other digital copy. Moreover, potential users can hardly be excluded from consumption. ${ }^{5}$

G enerally welfare economics calls for perfect market competition as this achieves optimal allocation of resources, however under certain hypotheses. These assumptions can $\{$ by and large $\{$ be expected to hold for many products of our economy. This is particularly true $\{$ and especially relevant in our case $\{$ for very homogenous products like books or music CDs. However, the transition from physical to digital information goods a Bects these basic assumptions. The appropriability of digital goods is seriously in question and they cannot be regarded as private goods anymore.

If we then ask the classic question of welfare economics again for digital goods, the answer will not be so clearly in favour of perfect market competition. A rrow (1962) analysed the welfare implications related to the production of knowledge. He shows that a free enterprise economy will under-invest in research, because the product can be appropriated only to a limited extent. The price set by the market will exceed the socially optimal one of zero marginal costs, one that would make everybody bene ${ }^{-} t$ from the research. He concludes that for optimal allocation to invention some organisation not governed by the pro $^{-} \mathrm{t}$-and-loss criteria $\{$ an alternative to the free market - needs to fund research.

Until recently research and its production of knowledge used to be the only commodity that matched the characteristics of a digital good, of course being in fact the quintessential information good. As described earlier the N ew E conomy introduces some products either entirely new as software or transformed from physical goods like digital music or e-books; all of them are digital information goods, though.

It is important to stress again the di ßerence between physical and digital information goods in terms of the property rights governance here. While our property rights system is designed for physical goods \{ correctly and with a lot of success $\{$ digital goods require a more nuanced property rights environment

\footnotetext{
${ }^{3}$ We will also cal I them digital goods or weightless goods as in related literature, but will focus on the term information goods. When necessary we distinguish them from physical information goods (information attached to a physical medium, e.g. a CD) by calling them digital information goods. When the sense is obvious we only use theterm information goods. Fol lowing Quah (2003) they are distingui shed from other goods by ${ }^{-}$ve characteristics: digital goods are non-rival, in ${ }^{-}$nitely expansible, discrete, aspatial and recombinant. More examples include videogames, DNA sequences, news, recipes, sports scores, visual images.

${ }_{5}^{4}$ Non-rival and non-excludable.

${ }^{5}$ Peer-to-peer- le sharing networks provide the online community with a huge amount of - les for free (among them copyrighted music and movie ${ }^{-}$les). The case of Napster is wellknown. However, o eshoots that emerged after its demise work without a central "le server and also exchange a great number of legal 'les. Recently a court ruled in favour of two onli ne services and for the ${ }^{-} r s t$ time against the Recording Industry A ssociation of A merica, recognising the legality of P2P services in a way. See Richtel (2003).
} 
to encourage a socially e \pm cient allocation. This system change appears particularly di \pm cult to understand for physical information goods that have been ${ }^{\circ}$ ourishing under ordinary property rights, but metamorphosed into digital information goods in the New Economy.

A number of digital goods are al ready being given away for free: E-books, open source software or computer shareware. However, this can generally be explained with positive promotional network e®ects that increase revenue indirectly and/ or a production that is primarily for personal use.

Some authors explicitly o Ber their e-books for free. The rationale here is a positive word of mouth eßect (a network externality) that increases the actual sales of the real book, the physical information good. The promotion erect is signi ${ }^{-}$cant and free downloads are massive ${ }^{6}$ W hat makes this work is the quality di ßerence betwen the e-book and an ordinary book. They can be regarded as complements, because the reading experience of a real book is so much better than reading the ebook on a scren. People with a high enough quality preference will buy the real book after getting to know it as a free ebook. Voluntary donations are not really intended here as they would bypass the publisher who is required for book production.

Contributions of code to open source software are intrinsically motivated. $\mathrm{Non-academic} \mathrm{literature} \mathrm{mentions} \mathrm{entertainment,} \mathrm{challenge} \mathrm{and} \mathrm{social} \mathrm{ties} \mathrm{as}$ the main motivation for programmers (Torvalds (2001)). Economically it can be explained with peer recognition concerns and potential lucrative jobs in the future if the coding is successful ( $L$ erner and T irole (2002)).

M ost computer shareware is programmed out of personal motivation: working out a better way for a simple speci ${ }^{-} \mathrm{c}$ software problem the coder encountered. G iving the software away for free supports the public domain with no additional costs. Takeyama (1994a) presents an empirical study of the shareware industry. The software is distributed under a voluntary payment scheme. The main " $n$ ding of the paper is that the distribution of returns has a positive expected value even when development costs (time) are considered. Therefore, potential voluntary contributions can make it worthwhile to program shareware.

The aforementioned reasons do not particularly apply to music products. The negligible quality di Rerence between conventional music products (CDs) and digital music (MP3s) makes them rather substitutes and not complements (as e-books are to real books). P ositive network eßects of free digital music can not be expected to have a signi ${ }^{-}$cant positive e ${ }^{\circledR e c t}$ on traditional sales, at least not in the long run. Moreover, making music is rather aimed at entertaining other people. It is not mainly for a personal purpose as computer shareware often is (initially).

However, volunt ary contributions from consumers like in the case of shareware might provide an alternative reward system to justify giving away music for free.

\footnotetext{
${ }^{6}$ Cory Doctorow's novel "Down and Out in the Magic Kingdom" at http:// www.craphound. com/ down/
} 


\subsection{Contract Theory Framework}

O ur model framework is set in contract theory, with the copyright holder of an information good as the principal and a consumer as the agent. Standard contract theory (as in models for the labour market with a ${ }^{-} \mathrm{rm} /$ manager as principal and a worker as the agent) deals with asymmetric information. The action the agent takes (e.g. e®ort) usually a ßects the output, but cannot be contracted on. The output, which is determined by eßort and some randomness, is used to write a contract to create incentives and make the agent exert opt imal eßort. In our setting there is no production function with a randomness term involved. Information asymmetry causes non-contractibility of the payment, not of an eßort. T his makes our principal agent situation somewhat more straightforward. The principal contracts directly on the action of the agent - if he is able to observe and verify the action, that is.

The simple relationship between copyright holder and consumer is based on the principal contracting with the agent to make a payment in exchange for the utility of consuming the music. We will see that this contractual relationship is very trivial for physical music goods (CDs), but far from that for "weightless" music (downloads).

Moreover, we integrate insights from the incomplete contracts literature in our framework. We compare complete contracts that specify all aspects of the relationship with contracts that are deliberately much less de ned. These endogenous incomplete contracts encourage reciprocal fair behaviour of socially minded agents. Fehr, G̈̈chter, Kirchsteiger (1997) conduct labour market experiments with ${ }^{-} \mathrm{rms}$ and workers. Three contracts are simulated that di ${ }^{\mathrm{Ber}}$ in the degree of incompleteness. E \&ort levels of workers were signi ${ }^{-}$cantly higher in the treatment with the least de ned contract. The contract that gives the opportunity for mutual reciprocity was found to improve e \pm ciency.

L ater Fehr and Schmidt (2000) apply their model of inequity aversion to a similar experiment featuring a manager as principal and a worker as agent. Contrary to the prediction of the self-int erest hypothesis incomplete contracts are 0 \&ered $\{$ in fact they are preferred $\{$ by the principals and reach a higher eßort level than complete contracts. ${ }^{7}$

Regner (2004) is another empirical analysis of endogenous incomplete contracts. The contract choices in a digital content labour relationship are analysed in a natural experiment.

\subsection{Social P references}

Social preferences explain economic behaviour moving away from the self-interest hypothesis of neoclassic economics. This departure is based on the results of a vast number of experiments conducted in recent years (see the surveys of Fehr and Schmidt (1999) and Camerer (2003)). However, the concept of social preferences goes back to the very beginning of modern economics $\{$ in fact,

\footnotetext{
${ }^{7} \mathrm{~A}$ more detailed description and analysis of the experiment can be found in Fehr, K lein, Schmidt (2001)
} 
literally even beyond that. Adam Smith already stressed the importance of other-regarding preferences in his "T heory of M oral Sentiments" .

W ithout a doubt economic motivation by self-interest does play a major role. The self-interest hypothesis can accurately explain economic behaviour in many areas. Predictions are particularly ${ }^{-}$ne the more competitive markets are and the more homogenous goods are. This is also con ${ }^{-}$rmed by experiments (Smith (1962)). On the other hand, many economic transactions are not about standardised goods and they are not taking place in a competitive market environment. The more personal the exchange is, the more other-regarding behaviour matters (see Smith (1998) and also F ehr and Schmidt (1999)).

Therefore, social preferences "assume people are self-interested, but are also concerned about the payo $\otimes S$ of others." (C harness and R abin (2002))

Several formal models have been developed recently to describe the role of fairness and reciprocity. Fehr and Schmidt (1999) and B olton and Ockenfels (2000) both use inequity aversion to explain other-regarding behaviour. M odels of int ention-based reciprocity like R abin (1993) or Dufwenberg and Kirchsteiger (2004) focus on the intentions of other agents and its impact on behaviour.

Social preferences in Charness and R abin (2002) combine the existing theory strands and contain three di ßerent motivations: a di ßer ence aversion component (agents want to reduce di ßerences between their and others' payo $\$ s$ ), concerns for social welfare (agents like to increase social surplus not just their private one) and a reciprocity part (a desire to raise or lower others' payo ${ }^{\circledR S}$ depending on how nice or not these behaved). The data of Charness and Rabin (2002) comes from 29 di ßerent games with 467 participants, making 1697 decisions. Their main goal is to get a better understanding of social motivations and its di ßerent ty pes in order to improve formal models that explain social prefer ences. From the statistical analysis of the experimental results they conclude that all three types are signi ${ }^{-}$cant, however to a di ßer ent extent. Social-welfare preferences appear to be the most dominant factor, followed by reciprocity and then di ßerence aversion. While we do not want to discuss speci ${ }^{-} \mathrm{c}$ details of their experiments, one of the results deserves particular spotlight in the context of our paper.

In game Barc7 player A can forgo a ( 750 for $A, 0$ for $B$ ) out come to give player $B$ the choice between $(750,400)$ and $(400,400)$. Only $6 \%$ of the B's choose $(400,400)$ here, while $30 \%$ of B's choose this option in the control game when $B$ 's choice follows either no move or a nasty move of player A. CR conclude the reason for this might be a very strong form of positive recipr ocity compared with di ßerence aversion. They conjecture that agents who have just been treated very kindly will not take Pareto-damaging action just to equalize payo ${ }^{\circledR}$. T hey also stress the resemblance to real world situations of this particular game. A lthough this is the result of just one game and more research needs to be conducted, the relevance of this result to our setting is interesting as will be shown in the next section. 


\section{The Model}

The model describes the relationship betwen a copyright holder and a consumer from the perspective of contract theory. We consider the transition process from a traditional music industry with physical goods to a music industry in the $\mathrm{New}$ Economy featuring digital goods. Therefore, we distinguish between four di ßerent contract cases.

The music market with physical goods allows for complete contracts. The transaction process of getting the product and paying for it is observable and enforceable.

In the digital age of information goods this transaction process becomes dif- cult to observe and we move to a world of asymmetric information. P rincipals can a) charge a monopolistic price and use strong copy protection to enforce the payment or b) strategically reduce the price to compete with pirated copies or

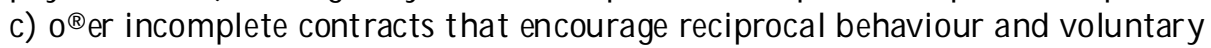
contributions.

\subsection{Set up of the model}

O ur simple principal agent model describes the relationship between a copyright holder $H$ and a consumer $C$. The utility $u$ to the consumer is his pleasure from listening to the music. How much utility he gets depends on each consumer as their preferences are heterogeneous. The payment to the copyright holder is denoted as $p$. In complete contracts this payment is equal to the price the copyright holder sets, whereas it can be zero under asymmetric information when piracy occurs. However, pirated copies cause some disutility $d$ to the consumers as they might be inconvenient to get and bear the risk of a virus attack. F inally, in incomplete contracts there is no price but instead possibly a voluntary contribution $v$ that $C$ can make.

Under asymmetric information $H$ has the option of implementing a monitoring scheme, which causes compliance costs $K>0$. This scheme increases the probability of the agent being convicted of copyright infringement from 0 to $s$. Getting caught as a pirate means a - nancial and moral damage of $f$ for the agent as a result from government prosecution. Without a monitoring system in place piracy is im possible to observe and the government cannot take action.

We assume both principal and agent to be risk-neutral. The participation constraint of the agent is $u, p$. The principal has to invest resources (time, money) to create the good. He has alternative sources of income and therefore we denote his investment as his reservation costs $R .^{8}$

After analysing the di ßerent contract cases we turn to the market for the music good, which is modelled as a two-stage game: one for production, one for consumption. The principal incurs the ${ }^{-}$xed costs ( $R$ and possibly $K$ ) in stage 1 and has to decide whether to produce the information good or not. In stage 2 the good is priced and consumed. The pricing is derived from the di ßerent

\footnotetext{
${ }^{8}$ In the related literature this term is also known as the cost of expression (Landes and Posner (1989) or the ${ }^{-} x e d$ cost of development ( $Y$ oon (2002)).
} 
contract designs. The costs incurred in stage 1 are sunk and will be ignored in the second stage. A private incentives and social welfare analysis follow.

\subsection{The Question of First-B est}

B efore analysing the four contract variations of the model, we want to focus attention for a moment on the general benchmark of a ${ }^{-}$rst best world.

In standard contract theory there exists a certain level of agent action (effort of a worker, for instance) that maximises total surplus. If information is symmetric, complete contracts can be written to obtain the "rst best. Under information asymmet ry though, agency costs arise and the optimal contract can only induce the agent to exert e ${ }^{\circledR}$ ort on a second best level. This logic naturally applies to the physical goods of the traditional music industry. Similar to the trade $0 \AA$ between incentives and risk that reduces the e ${ }^{\circledR}$ ort of a worker or the costly monitoring scheme that keeps eßort at a certain level, the costs of the product would increase, if the payment transaction were not observable and action to enforce paying had to be taken.

However, the ${ }^{-}$rst best criterion in markets for digital information goods is di ßerent. Remember that an additional copy can be produced at negligible costs; the marginal costs are zero. In the ${ }^{-}$rst best world the price would equal marginal costs as this maximises total surplus. We still have to consider the issue of dynamic e \pm ciency \{ motivation to produce information goods in the - rst place (when there is no price charged) $\{$ but it is already clear that under information asymmetry a positive price cannot lead to a ${ }^{-}$rst best allocation of the information good, only to a second best.

A gain, complete contracts \{ imaginable under perfect information, though not realistic $\left\{\right.$ deliver ${ }^{-}$rst-best results as they would allow perfect ${ }^{-}$rst-degree price discrimination.

\subsection{Contract Designs}

\subsubsection{Physical Information Goods}

Under perfect, symmetric information about the payment complete contracts can be written in the traditional music environment. The analysis under complete contracts is very straightforward and mainly serves for a better understanding of the bigger picture.

In this situation the principal $H$ has a constant but positive cost of production $c$. R emember that the physical good is not costless to reproduce in contrast to the digital good. We abstract from occasional shoplifting and assume that the agent's action of paying for the product is perfectly observable. Thus, a complete and easily enforceable contract can be written. ${ }^{9}$

The market allocation under perfect competition with explicit contracts would deliver ${ }^{-}$rst best results for physical goods. In reality the traditional music industry is a rather concentrated market in which the ${ }^{-}$ve biggest ${ }^{-} \mathrm{rms}$

\footnotetext{
${ }^{9}$ enabled by the well-working property rights system.
} 
(the major labels U niversal, T ime Warner, EMI and Sony and BM G who have agreed to merge) combine for around $80 \%$ of the market share. In fact, they were even found to collude on prices for CDs in the USA recently. ${ }^{10}$ Monopolistic price setting appears fair to assume in the industry. The condition for the optimal contract is in ${ }^{\circ}$ uenced by the market power and thus deviates from the $\mathrm{e} \pm$ cient case of $p=c$ that would otherwise be possible.

\subsubsection{Digital Information Goods}

The following three cases describe the music business in the New Economy. The implications of this transition for the model are twofold: physical $(c>0)$ convert to digital information goods $(c=0)$ and perfect information (certainty about payment) is followed by asymmetric information with uncertainty about receiving the charged price.

The copyright holder does not possess the means to observe the transaction of the good as easily as he used to do in the traditional industry. He becomes the principal and faces a situation of moral hazard as consumers now have the alternative of ${ }^{-}$le sharing. They can obtain the digital good without paying for it. The agents' payment for the principal's product becomes non-veri ${ }^{-}$able.

Strong Copy Protection Pirated music is widely available in networks and consumers can download songs for free. The copyright holder cannot contract on the payment. However, the principal can introduce what is known in the literature (see for example M acho-Stadler and P erez-C astrillo (2001)) as a veri ${ }^{-}$cation technology. He implements a monitoring system that helps to detect consumers who do not pay, but rather use the P2P software. This investment in veri ${ }^{-}$cation technology makes copying veri ${ }^{-}$able at a certain probability $s$. To simplify things we assume that this signal (being caught) is perfect and always results in litigation of the agent in court for copyright infringement. ${ }^{11}$ The punishment $f$ is exogenous as it is set by legislation. ${ }^{12}$ However, it is supposed to work as a threat only as it should keep the agent from pirating. At the optimal price the agent chooses to buy the product, since the risk of getting caught when copying is too high for him. The agent also takes into account that copying causes transaction costs. The quality of the downloaded music ${ }^{-}$le cannot be veri ${ }^{-}$ed before and it might be a bad recording. As a result the user might want to get another pirate copy. This is time-consuming and his inconvenience increases. The downloader also runs the risk of getting a "le

\footnotetext{
${ }^{10}$ More information about this case and the settlement is available at http:// www.musiccdsettlement.com/ english/

${ }^{11}$ The ${ }^{-}$rst direct legal action against individuals was a lawsuit of the Recording Industry Association of A merica against four coll ege students who were running $\backslash$ mini-Napsters" or online di rectories on their computers, facilitating ${ }^{-}$le sharing for fellow students on the university network. See Harmon (2003). In the meantime over 2,000 consumers have been taken to court by record company associations.

${ }_{12}$ We assume that the ${ }^{-}$ne has to be paid to the government. This could be di Berent for civil lawsuits. However, a business model based on suing consumers is not an option for copyright holders.
} 
that is infected with a virus and which might in turn damage his computer. $M$ oreover, one could also think of moral burdens that come with something not exactly approved by society. We aggregate these transaction costs in the disutility from copying $d$, which is constant over individuals.

Naturally, it is costly to implement the veri ${ }^{-}$cation system. The huge tra $\pm c$ of $P 2 P$ networks needs to be monitored and tracked which is technologically very demanding. ${ }^{13}$ Also the identity of online users has to be revealed by the internet service provider which poses some legal complications. ${ }^{14}$ We denote the ${ }^{-}$xed cost of implementing a monitoring system as the compliance costs $K$.

$P$ ayo ${ }^{B S}$ are (using a single, representative consumer and without sunk costs):

$$
i_{H}=p \text { and }{ }_{C}=u \mathbf{i} p \text { if } p \cdot s f+d
$$

and

$$
{ }_{H}=0 \text { and }\left.\right|_{C}=u \mathbf{i} s f \mathbf{i} d \text { if } p>s f+d
$$

If the threat of the punishment is meant to work, the principal must set a price lower or equal to the expected damage to the agent plus the disutility from copying. Instead, the agent chooses to copy, when the price she is charged exceeds the risk of getting punished.

The incentive compatibility constraint for the agent is: $p_{m o n} \cdot s f+d$

Strategically Low Pricing A nother option for the principal is to accept the fact that digital copies of the product are readily available through ${ }^{-}$le-sharing P2P networks. Illicit copying is tolerated and not actively prosecuted. Instead he competes with pirated copies by setting a low price. It follows that the principal does not invest in the monitoring system and no compliance costs occur.

Although pirated copies are for free, they do cause some costs for the consumers. Notice that the quality of consumption is equal no matter if it is a direct copy or pirate copy. It is the transaction cost that is di Berent, though. As explained above we aggregate these transaction costs in the disutility from copying $d$, which is constant over individuals.

All these costs for the consumer occur if the product comes from piracy, they do not if the product comes directly from the principal. Thus, a reasonable strategy for the principal would be to take advantage of this utility di ßerence and o Ber the product for a very low price that matches the consumer's disutility from copying $\{$ as long as this still covers his reservation costs. The pricing

\footnotetext{
${ }^{13}$ The music industry is very active to develop electronic countermeasures against online piracy; some of them legal, some illegal. See Sorkin (2003) and also Wired (2003)

${ }^{14}$ The Recording Industry A ssociation of A merica is in a legal battle with Verizon $\{$ a maj or internet service provider. It claims recent legislation obligates Verizon to reveal the names of customers if they are suspected of infringement. Verizon argues the law violates freespeech and due process rights protected by the Constitution. See New York Times (2003). Recently a Canadian court ruled that internet service providers are not required to pass on user identities. SeeP2Pnet (2004).
} 
should be so attractive that buying the high quality product is more convenient than getting a low quality copy for free ${ }^{15}$

The copyright holder cannot charge more than the monetary equivalent of the disutility from copying. Otherwise, the consumer will opt to pirate music instead of buying it legally.

$P$ ayo ${ }^{\circledR S}$ are:

$$
\left.\right|_{H}=p \text { and }{ }_{C}=u \mathbf{i} p \text { if } p \cdot d
$$

and

$$
{ }_{H}=0 \text { and }\left.\right|_{C}=u \text { i } d \text { if } p>d
$$

The incentive compatibility constraint is: $p_{l o w} \cdot d$

This contract gives the copyright holder a pro ${ }^{-} t$ equivalent to $d$. The consumer gets a utility of $u \mathbf{i} d$, which is equal to his reservation utility from copying.

Voluntary Reciprocal Contributions Finally, the principal can o $\mathbb{R}$ er the product for fre relying on enough voluntary contributions motivated by consumers' social preferences that cover or exceed his reservation costs. It seems important to stress again that only because of the particular characteristics of digital information goods he has this choice. This could not work with physical goods since giving these away is costly, giving away digital goods is not.

In contrast to a complete contract a deliberately left-open contract leaves room for reciprocal behaviour between the agents.

The fact that the principal o Bers the product for free $\{$ despite other options $\left\{\right.$ is regarded as kind behaviour in the eyes of the consumer. ${ }^{16} \mathrm{~A}$ fair-minded consumer $\{$ one with social preferences $\{$ will recognise and appreciate the eßort of the principal and will reciprocate. He contributes voluntarily. Obviously, he will only give a fraction of his actual utility from the song and he will certainly not contribute, if he ${ }^{-}$nds out he does not like the music at all. On the other hand, a sel ${ }^{-}$sh consumer does not care about the income of the principal nor about any kind behaviour towards him. He does not contribute and free rides.

In the literature of behavioural economics usually a ratio of $60 \% \mathrm{sel}^{-} \mathrm{sh}$ to $40 \%$ fair-minded individuals is assumed (Fehr and Schmidt (1999), Charness

\footnotetext{
${ }^{15}$ T he iTunes M usi c Store run by A pple Inc. appears to follow this strategy. It o ßers music downl oads for a moderate price and without usage restrictions. It has been the ${ }^{-}$rst successful online music store and has already been imitated. See www.itunes. com

${ }^{16}$ It is important to poi nt out that this only applies to genuinely free products. When a free version is meant to boost the revenues from complementary products instead (as described in section 2.1), consumers will have much less sympathy with the principal if at all. Consumers who realise that the product is nothing but a loss-leader will not perceive the principal's free o fifering as a kind gesture.

The same is true for consumers. We assumethey are genuinely kind. They give a voluntary contribution and do not spread the "le in P2P networks (which could be seen as unkind behaviour).

Another way to look at this is that consumers do not care from where they got a music ${ }^{-}$le. Once they enjoy it and are willing to reciprocate, they do not mind if they got it di rectly from the artist or via a P 2P network. It is then bene- cial for the principal, if consumers spread the ${ }^{-}$le.
} 
and R abin (2002)). We adopt this measure and denote the ratio of individuals with social preferences as $\alpha$.

However, experiments suggest that reciprocal behaviour of individuals is even stronger when the amount of eßort involved in the relationship (known as "earned property rights" (Fahr and Irlenbusch (2000), V. Smith (1998) among others) is taken into account. Experimental subjects are asked to do some trivial extra work to earn their endowment. This is common knowl edge among the subjects. The results show that individuals appear to acknowl edge when the other party had to work for the endowment and they send more money back. In the same way consumers know that artists have put in eßort to provide the information good. Moreover, the social, personal transaction between the art ist and a consumer instead of an impersonal market exchange with a record label matters, if the copyright holder is the artist (V. Smith (1998)).

These factors a Rect the willingness of individuals to reciprocate and we sum them up in the parameter $\lambda$.

There is one more reason why an ex post payment for music (a voluntary contribution) could be preferred to the common ex ante payment (the charged price). Information goods are experience goods. Consumers do not know what they are worth to them until they experience them (Shapiro and Varian (1999)). Their exact value to the consumer is quite unknown ex ante. The valuation rather develops until the good has been experienced often enough and the true worth has been established.

This generally applies to information goods, but to music in particular. Listening to one song is much more likely to be a frequently repeated activity in contrast to watching one movie. Often people realise how much they like a certain song only after quite some time. M or eover, the volatility of quality matters. For instance, the quality of a newspaper will be rather stable over time and thus people do not mind paying for it in advance. Quality of the output of an artist is more likely to change over time or it might appeal to di Berent groups of consumers. F inally, well-established artists can ask for ex ante payments thanks to their reputation. On the other hand, ex post payments might be more interesting to new artists who have not built a reputation yet. Thus, the expected utility or the marginal willingness to pay ex ante can be signi ${ }^{-}$cantly lower than utility ex post.

In order to incorporate social preferences in this context we focus on reciprocity. As mentioned before other motivations of socially minded individuals exist - like concerns for social welfare and inequity aversion - and they have also been expressed in theoretical models. However, describing the true cause of social preferences is not the aim of this paper. Furthermore, we believe that reciprocity plays a major role in the context of our model. That is why we limit socially minded behaviour to reciprocity.

We integrate reciprocity based on the seminal work of $R$ abin (1993) for normal form games and its extension Dufwenberg and Kirchsteiger (2004) for extended form games. The utility function of socially minded individuals increases not only in their material payo ${ }^{\circledR S}$ but also in the psychological payo ${ }^{\circledR S}$ which depend on the individuals' kindness to others and beliefs about that. 
The resulting games are solved using the psychological games framework of G eanakoplos, Pearce and Stacchetti (1989). While the action set $a_{i}$ describes the choices of player $i$ (e.g. the selected contract design of the copyright holder or the payment decision of the consumer), $b_{i j}$ de- nes the belief of $i$ about the choices of player $j$, whereas $c_{i j i}$ is $i$ 's belief about what $j$ believes are $i$ 's choices. This framework of beliefs allows us to express the kindness $\kappa_{i j}$ and beliefs about the kindness $\mathbf{e}_{i j i}$ of individuals towards another individual which are then integrated into the utility function of individuals with social preferences. This concept has been applied and described in detail in R egner (2004) for a similar digital content framework.

The adjusted utility function contains a material payo $®$ as the ${ }^{-}{ }^{-}$st term and the reciprocity payo ${ }^{\circledR}$ in the second term that is weighted by the sensitivity of reciprocity $\alpha$ ( $\alpha=0$ is the special case of pure self-interest).

$$
U_{c}={ }_{c}\left(a_{c}, b_{c h}\right)+\alpha \phi \kappa_{c h}\left(a_{c}, b_{c h}\right) \phi \mathbf{e}_{c h c}\left(b_{c h}, c_{c h c}\right)
$$

The "material payo $\mathbb{B}^{\prime}$ of the consumer is the pleasure $u$ from listening to the music minus what he pays to the copyright holder. For instance ${ }_{c}=$ $u \mathbf{i} p$ if a price is charged and paid. $\left.\right|_{c}=u$ if the download is available for free and the consumer does not give a voluntary contribution (free rides). The material payo ${ }^{\circledR}$ is ${ }_{c}=u \mathbf{i} v$ if the consumer decides to give a voluntary contribution. Only the case of the endogenous incomplete contract without a - xed price is interesting for our analysis. That means the copyright holder is kind to the consumers. He could have set a price and enforced it, but instead he opted to make the music freely available. This perceived kindness of $H$ to $C$ is expressed by a positive value of $\mathbf{e}_{c h c}$. It would be negative, if $H$ were unkind and had charged a price instead. In the same way the kindness of the consumer towards the copyright holder $\kappa_{c h}$ takes a positive value, if $C$ makes a voluntary contribution to $H$. If the consumer free rides, he is unkind and $\kappa_{c h}<0$. It follows that the reciprocity payo $\AA$ is positive, when the perceived kindness of $H$ is answered with kindness by $C$. It is also positive, if $H$ is believed to be unkind and then $C$ is unkind, too. Essentially utility is increased by reciprocity when the sign of an individual's kindness $\kappa$ matches the sign of the perceived kindness of the other individual (e).

Of course, in the case of purely self-interested individuals $(\alpha=0)$ this has no impact on the utility of the consumer. However, socially minded consumers will wish to treat $H$ kindly, if their preference for fairness ( "bought" with the voluntary contribution $v$ ) o Bsets their material loss of being kind (paying $v$ ). If this trade $0 \circledR$ is not strong enough, material pursuits override fairness concerns even if individuals have social preferences. The consumers' decision to make a voluntary contribution depends on:

$$
U_{c}^{v}=\left(\begin{array}{ll}
u \mathbf{i} & v
\end{array}\right)+\alpha \Phi \kappa_{c h}^{v} \phi \mathbf{e}_{c h c}^{V C}>u+\alpha \phi \kappa_{c h} \phi \mathbf{e}_{c h c}^{V C}=U_{c}
$$

The perceived kindness of $H$ is $\mathbf{e}_{c h c}^{V C}$ and it is positive, because $H$ has chosen the kind option of the end ogenous incomplete contract. The consumer's kindness to $\mathrm{H}$ is $\kappa_{c h}^{v}>0$ when he makes a contribution and it is $\kappa_{c h}<0$ when he decides 
against that and free rides. To simplify the analysis we assume that individuals only have a discrete choice of the contribution $v$ they make. It is a ${ }^{-}$xed fraction of their actual utility: $v=\lambda u$. Furthermore, we assume that being purely selfinterested means $\alpha_{s}=0$ and being a fair-minded consumer translates into $\alpha_{f}$ where $\alpha_{f}$ is large enough that for socially-minded consumers $U_{c}^{v}>U_{c}$ always holds. They prefer to make a contribution $v=\lambda u$. For self-int erested consumers $U_{c}^{v}<U_{c}$ is always true and they never contribute.

W hile en dogen ous incomplete contracts with contributing consumers can be regarded as the positive reciprocity equilibrium of the game, a charged price enforced by ' ne and ${ }^{-}$le sharing consumers represent the nasty or negative reciprocity equilibrium. The strategically low price of our model can be regarded as an option to which consumers are neutral.

In general terms the principal expects to receive $v=\alpha \$ \lambda u$ when he o ers the endogenous incomplete contract to a consumer.

We al ready mentioned one speci ${ }^{-} \mathrm{C}$ game of $C$ harness and $R$ abin (2002) that delivered surprising results and calls into question the prevailing doubts regarding positive reciprocity shown in conventional games studied. A nother of their games, Berk 14, appears to be an even closer ${ }^{-} t$ for the simpli ${ }^{-}$ed payo ${ }^{\circledR}$ of our model and underlines the signi ${ }^{-}$cance of positive reciprocity: Player $A$ chooses between a ( 800 for A, 0 for B ) outcome and giving player B the choice between outcomes $(0,800)$ and $(400,400)$. $55 \%$ of the B's make the balanced choice here, while only $22 \%$ of B 's choose this option in the controlled version (a pure dictator game) without a kind 'rst move of player $A$.

T his supports the intuition of our scenario as modelled above. The principal has the choice between two outcomes. O ne gives him the bulk of the surplus and leaves not much for the agent. The second lets the agent decide between two options. He can "cheat" and abuse the trust (no payo $®$ for the principal, everything for the agent) or he can share the bene ${ }^{-} t$ with the principal by contributing voluntarily. Following the kind ${ }^{-}$rst move of the principal (he forgoes trying to enforce a high price) the agent is more likely to return the kindness and act reciprocally.

A gain, transaction costs as in ${ }^{-}$le sharing use do not play a role when the principal makes the product freely available on his web site. Thedirect download from the site of the copyright holder or a licensed intermediary is quick and of high quality. Naturally, the endogenous incomplete contract does not feature a price. However, fairness and reciprocity might be regarded as an enforcement device of the deliberately left open contract. No consumer is deprived of a potential bene ${ }^{-} t$ with the price equal to marginal cost. Voluntary contributions to the principal can exceed his reservation costs and motivate him to o ${ }^{\circledR e r}$ his products for free.

\section{A nalysis of the market}

This section applies the presented contracts to the market for digital music. 


\subsection{Market Demand}

We model the market in a very basic way, similar to B esen and K irby (1989) or Yoon (2002). Demand is linear and downward sloping. Consumer's preferences for music are heterogeneous and their valuations are uniformly distributed over the interval $[0, a]$. Consumption is $n$ units per person, there are $N$ potential music consumers and the maximum quantity of music demanded is $q=n N$. We assume $d$ to be strictly less than the price in the copy protection case. 0 therwise strong copy protection is useless to analyse since no protection is necessary to set the optimal price for the principal. A numerical example will follow later to illustrate the cases.

The principal wants to maximise pro ${ }^{-}$ts and will develop the product if and only if the revenue in the consumption period covers the ${ }^{-}$xed costs of stage 1. Naturally, in all contract cases this is the reservation cost $R$. Additionally the compliance costs $K$ are incurred in the strong copy protection case.

Remember that any ${ }^{-}$xed costs incurred in stage 1 are sunk in stage 2 and that marginal costs are zero.

The demand function is: $p=a \mathbf{i} b q$

A ssumption 1: $K>0$

A ssumption 2: $d<\frac{a}{2}$

\subsubsection{Strong Copy P rotection}

The incentive compatibility constraint of $p_{\text {mon }} \cdot s f+d$ restricts the price in the copy protection case. M oreover, the principal would like to use a monopolistic pricing policy of $p_{M}=\frac{a}{2}$ to maximise the pro ${ }^{-}$t. The price under strong copy protection is therefore de ned as:

$$
p_{C P}=\min \left(p_{M}, p_{\text {mon }}\right)
$$




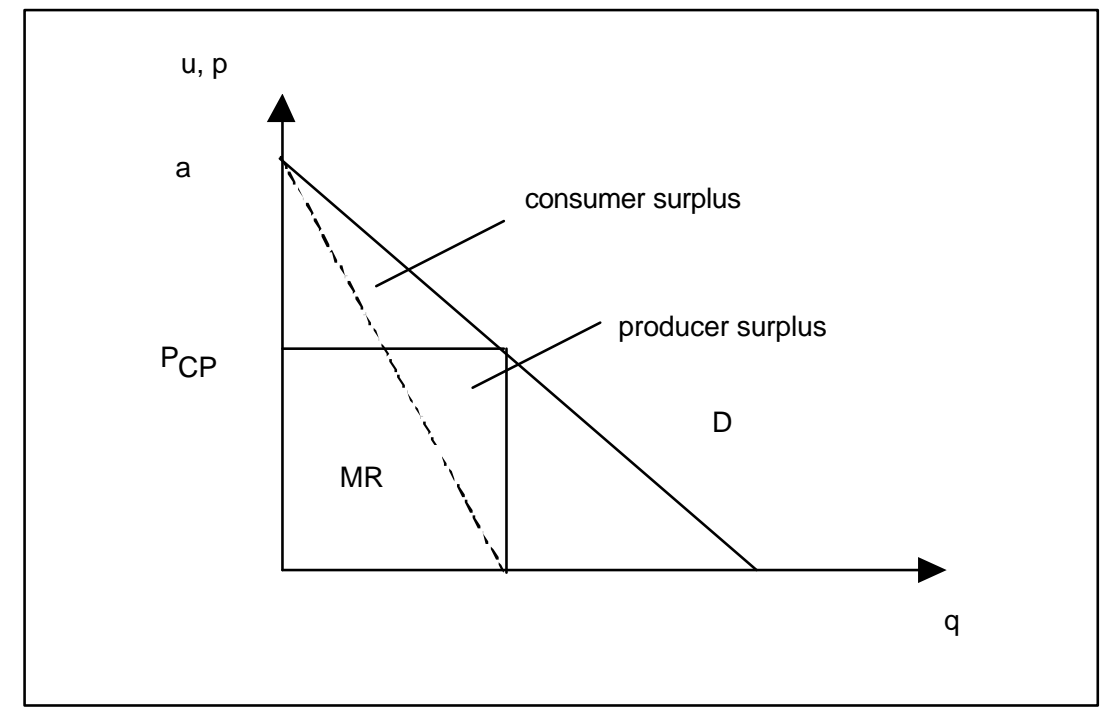

Figure 1: Supply and demand under strong copy protection

If the threat of punishment is not a binding condition for the price, then the principal can set the monopoly price of $p_{M}=\frac{a}{2}$. He maximises revenue and his surplus is $P S_{C P}=\frac{a^{2}}{4 b}$. Consumer surplus is $C S_{C P}=\frac{a^{2}}{8 b}$ and the usual deadweight loss results. Some consumers are excluded from consumption due to a price higher than marginal cost.

If the pro ${ }^{-}$t maximising monopoly price $p_{M}$ cannot be enforced, because the threat of punishment is not strong enough, the principal will have to settle on $p_{m o n}$ at which consumers are indi ßer ent between buying and downloading. $\mathrm{His}$ surplus would then be $P S_{C P}=(s f+d)(a \mathbf{i}(s f+d)) \frac{1}{b}$.

\subsubsection{Low Price}

If the principal decides to compete with copies obtainable in P2P networks, her price cannot exceed the disutility agents experience from copying:

$$
p_{\text {low }} \cdot d
$$

As mentioned before we assume these transaction costs (the virus risk, moral issues, inconvenience from downloading) to be constant across consumers. Technically, demand is perfectly elastic at $d$ and it is easy to see that in the monopolistic environment for realistically small values of $d$ the pro ${ }^{-} t$ maximising price the principal chooses will equal $d$. 
$u, p, d$

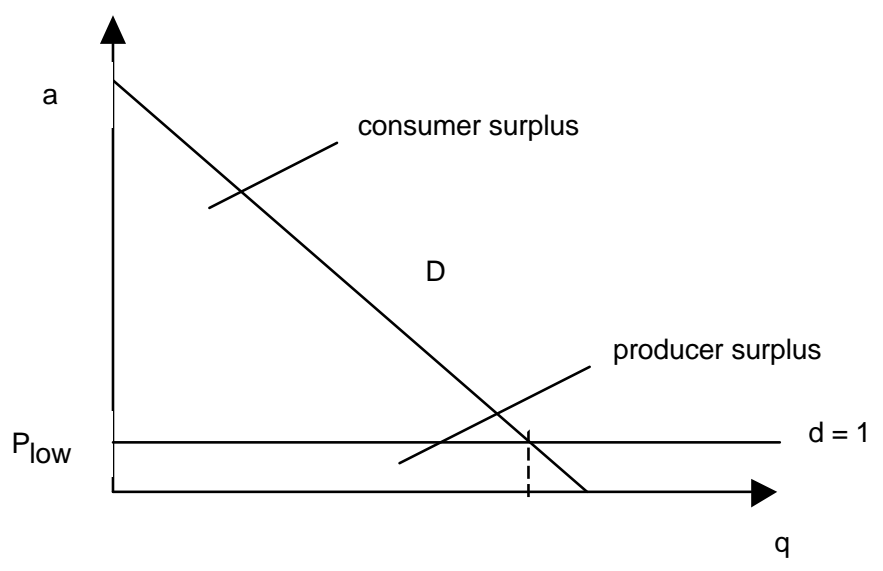

Figure 2: Supply and demand with a st rategically low price

B eing forced to set a very low price the $\mathrm{pro}^{-} \mathrm{t}$ of the principal shrinks significantly. R ecall however that no compliance costs are incurred. W ith our linear demand a price of $d$ results in a revenue of $P S_{\text {low }}=\frac{d}{b}(a \mathbf{i} d)$. The consumer surplus is $C S_{\text {low }}=\frac{1}{2 b}(a \mathrm{i} d)^{2}$. Fewer potential consumers are kept from a bene- cial trade than under strong copy protection.

\subsubsection{Voluntary Reciprocal Contributions}

There is no price charged in the case of endogenous incomplete contracts. Revenue for the principal comes from voluntary contributions by agents. These payments are determined by the social preferences parameter $\lambda$ and the ratio of fair-minded consumers $\alpha$, but also depend on the actual utility each consumer gets from listening. 


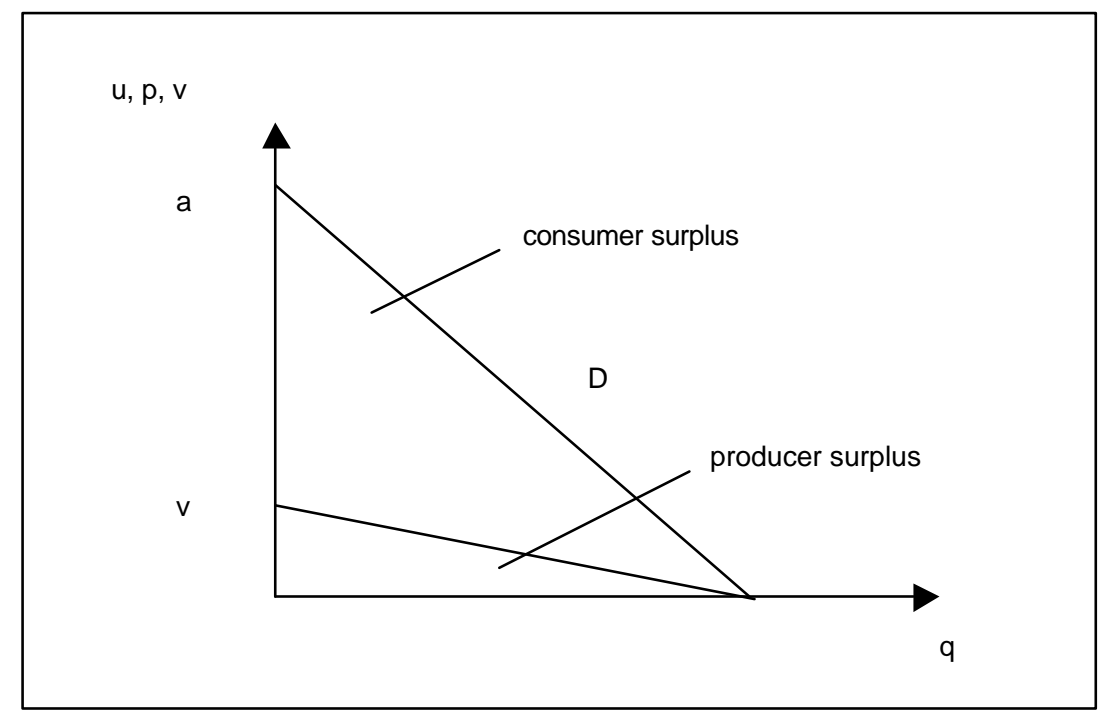

Figure 3: Supply and demand with voluntary contributions

W ith a price of zero no consumer is excluded from the ben $e^{-} t$ of the product. $D$ eadweight loss is eliminated and $\left\{\right.$ at ${ }^{-}$rst $\{$consumers receive the entire surplus. However a fraction $\alpha$ of consumers returns $\lambda$ of their utility $u$ to the copyright holder because of their social preferences. A gain, we transform $\alpha$ into the probability of each consumer to reciprocate. Voluntary contributions amount to $P S_{V C}=\frac{1}{2 b} \alpha \lambda a^{2}$ and are the principal's revenue. The remaining consumer surplus is $C S_{V C}=\frac{a^{2}}{2 b}(1 \mathrm{i} \alpha \lambda)$.

\subsection{A nalysis of $\mathrm{P}$ rivate Incentives}

The principal's revenue and costs determine the private incentives to invest. He selects the contract design that promises the highest pro ${ }^{-} t$.

$$
\mathrm{i}=P S \mathbf{i} R \mathbf{i} K
$$

We analyse under which parameter values each contract design maximises pro ${ }^{-}$t. $K$ is replaced with $\frac{k}{b}$ in the calculations.

T wo di ßerent sub-cases are possible under strong copy protection and we distinguish between them in the analysis. When the threat of punishment is strong enough to enforce the monopoly price, we calculate with $p_{M}$ and ${ }_{C P}=$ $\frac{\left(\frac{a}{2}\right)^{2}}{b}$ i $R$ i $K$. Alternatively, we use $p_{m o n}$ and ${ }_{C P}=\frac{(s f+d)(a \mathrm{i}(s f+d))}{b}$ i $R$ i $K$. B oth sub-cases are considered in order to calculate the conditions for the optimality of strong copy protection. These are su \pm cient conditions. We restrict the analysis to strong copy protection with a monopoly price when we determine the optimality conditions of a strategically low price and of voluntary contributions. These are necessary conditions. 


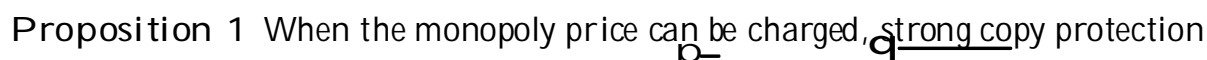
is the optimal choice if and only if $d \cdot \frac{a}{2} \mathrm{i} \quad \mathrm{P}_{k}$ and $a, \frac{4 k}{\left(1_{\mathrm{i}} 2 \alpha \lambda\right)}$ for $\alpha \lambda<\frac{1}{2}$.

$W$ hen the price charged equals the threat of punishment, strong copy protection is the optimal choice if and only if $d \cdot \frac{a}{2} \mathrm{i} \frac{s f}{2} \mathrm{i} \frac{k}{2 s f}$ and $\frac{(s f+d)}{\alpha \lambda} \mathbf{i}$

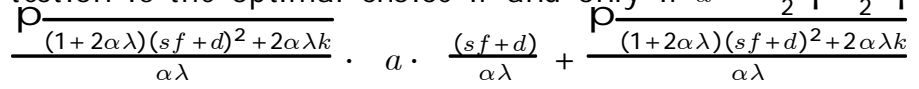

P roof. a) The principal's revenue of strong copy protection is determined by the monopoly price $\left(p_{m o n}, p_{M}\right)$ :

$$
\begin{gathered}
\text { i CP, low } \\
\frac{\left(\frac{a}{2}\right)^{2}}{b} \mathbf{i} R \mathbf{i} K, \frac{d(a \mathbf{i} d)}{b} \mathbf{i} R \\
d^{2} \mathbf{i} a d+\left(\left(\frac{a}{2}\right)^{2}+k\right), 0 ; \text { with } k=b K \\
d \cdot \frac{a}{2} \mathbf{i} \frac{\mathrm{p}_{-}}{k}
\end{gathered}
$$

The case $d, \frac{a}{2}+{ }^{\mathrm{p}} \bar{k}$ can never occur because of the assumption $d<p_{M}$.

$$
\begin{gathered}
\frac{\left(\frac{a}{2}\right)^{2}}{b} \text { i } R \text { i } K, \frac{a^{2} \alpha \lambda}{2 b} \text { i } R \\
\frac{1}{4} a^{2} \text { i } \frac{1}{2} a^{2} \alpha \lambda \text { i } k, 0 \text {; with } k=b K \\
a, \quad \frac{4 k}{(1 \mathrm{i} 2 \alpha \lambda)} \text { if: } \alpha \lambda<\frac{1}{2}
\end{gathered}
$$

If $\alpha \lambda, \frac{1}{2}$, then the monopoly surplus is already smaller than the revenue from voluntary contributions without taking $K$ into account (the condition $\left.\right|_{C P}=\frac{\left(\frac{a}{2}\right)^{2}}{b} \mathrm{i} R \mathrm{i} K>\frac{a^{2}}{4 b} \mathrm{i} R=i_{V C}$ cannot hold since $K$ is de ned to be positive). However, the necessary parameter conditions are rather implausible. Every consumer would have to contribute half of his utility. Otherwise, strong copy protection generates more pro ${ }^{-} t$ for the principal than the voluntary contributions case, if $a, \quad \frac{4 k}{\left(1_{\mathrm{i}} 2 \alpha \lambda\right)}$ and $\alpha \lambda<\frac{1}{2}$.

b) The principal's revenue of strong copy protection is determined by the threat of punishment $\left(p_{m o n}<p_{M}\right)$ :

$$
\begin{gathered}
\text { l } C P, \text { low } \\
\frac{(s f+d)(a \mathbf{i}(s f+d))}{b} \mathbf{i} R \mathbf{i} K, \frac{d(a \mathbf{i} d)}{b} \mathbf{i} R \\
s f(a \mathbf{i} s f \mathbf{i} 2 d) \mathbf{i} k, 0 ; \text { with } k=b K
\end{gathered}
$$




$$
\begin{aligned}
& d \cdot \frac{a}{2} \text { i } \frac{s f}{2} \text { i } \frac{k}{2 s f} \\
& \text { | } C P, \mid V C \\
& \frac{(s f+d)(a \mathbf{i}(s f+d))}{b} \text { i } R \text { i } K, \frac{a^{2} \alpha \lambda}{2 b} \text { i } R \\
& (s f+d)(a \mathbf{i}(s f+d)) \mathbf{i} \frac{1}{2} a^{2} \alpha \lambda \mathbf{i} k, 0 \text {; with } k=b K \\
& \frac{(s f+d)}{\alpha \lambda} \mathrm{i} \frac{\mathrm{p} \frac{(1+2 \alpha \lambda)(s f+d)^{2}+2 \alpha \lambda k}{(1+2 \alpha \lambda}}{\alpha \lambda} \cdot a \cdot \frac{(s f+d)}{\alpha \lambda}+\frac{\mathrm{p} \frac{(1+2 \alpha \lambda)(s f+d)^{2}+2 \alpha \lambda}{(1+2)}}{\alpha \lambda}
\end{aligned}
$$

The disutility of copying $d$ has to be more than $\mathrm{p}_{\bar{k}}$ (or respectively $\frac{s f}{2}+\frac{k}{2 s f}$ in b)) below the monopolistic price to make strong copy protection superior to the low price design. Moreover, strong copy protection has to generate more pro $^{-} t$ than endogenous incomplete contracts. The compliance costs must not be too high in the case of the monopoly price. In b) the highest possible valuation of a consumer $(a)$ cannot be too far above or below the enforceable price $\left(p_{\text {mon }}=\right.$ $s f+d$ ) divided by the reciprocity parameters $(\alpha \lambda)$. This distance also depends on the compliance costs.

$\mathrm{P}$ roposition 2 The option of strategic pricing is optimal if $d>\frac{a}{2} \mathrm{i}^{\mathrm{P}} \bar{k}$ and $\frac{1_{i} p \frac{p}{1_{i} 2 \alpha \lambda}}{\alpha \lambda} \cdot \frac{a}{d} \cdot \frac{1+p \frac{p}{1_{i} 2 \alpha \lambda}}{\alpha \lambda}$ for $\alpha \lambda<\frac{1}{2}$

P roof.

$$
\text { | low }>\text { i } C P
$$

See equations 7 to 10 in the ${ }^{-}$rst half of Proposition 1 's proof a).

$$
d>\frac{a}{2} \mathrm{i} \quad \mathrm{p}_{\bar{k}}
$$

The case $d<\frac{a}{2}+\mathrm{P}_{\bar{k}}$ is always true because of the assumption $d<p_{M}$.

$$
\begin{gathered}
\text { ! low, } V C \\
\frac{d(a \mathbf{i} d)}{b} \mathbf{i}, \frac{a^{2} \alpha \lambda}{2 b} \text { i } R \\
\alpha \lambda a^{2} \mathbf{i} 2 d a+2 d^{2} \cdot 0 \\
\frac{a}{d} \cdot \frac{1+\mathrm{p} \frac{2 \alpha \lambda}{1 \mathrm{i} 2 \alpha}}{\alpha \lambda}
\end{gathered}
$$

or

$$
\frac{a}{d}, \frac{1 \mathrm{i}}{\alpha \lambda} \frac{\mathrm{p}}{1 \mathrm{i} 2 \alpha \lambda}
$$

$V_{V C}$ is strictly superior to low, if $\alpha \lambda, \frac{1}{2}$ because of assumption 2 . 
In order for low strategic pricing to be befter than strong copy protection the disutility of copying $d$ has to be less than $\bar{k}$ below the monopolistic price. 0 nly then does the revenue from strategic pricing exceed the monopoly pro $^{-} t$. $T$ he second condition guarantees that the strategically low price creates better incentives than the voluntary contributions design.

P roposition 3 Endogenous incomplete contracts to encourage yoluntary contributions are optimal (i) if $\alpha \lambda, \frac{1}{2}$ or (ii) for $\alpha \lambda<\frac{1}{2}$ if $a<\frac{4 k}{\left(1_{\mathrm{i}} 2 \alpha \lambda\right)}$ and

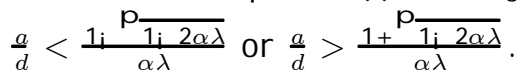

$\mathrm{P}$ roof.

or

$$
\begin{gathered}
\mid V C>C P \\
\alpha \lambda, \frac{1}{2}
\end{gathered}
$$

$$
\text { if } a<\frac{\mathrm{s}}{\frac{4 k}{(1 \mathrm{i} 2 \alpha \lambda)}} \text { and } \alpha \lambda<\frac{1}{2}
$$

See equations 11 to 14 and explanation in the second half of Proposition 1's proof a).

$$
\text { i } V C>\text { i low }
$$

See equations 19 to 23 in the second half of Proposition 2's proof.

The voluntary contributions design is optimal, if $\alpha \lambda, \frac{1}{2}$. In this case no other design can exceed the revenue generated by endogenous incomplete contracts. Otherwise, it is superior to strong copy protection, if the compliance costs $K$ are too high. Moreover, it must create a higher pro't than under strategic pricing to make it the optimal contract.

\subsection{Social Welfare A nalysis}

The optimal contract design is the one that maximises social welfare subject to its revenue from consumption being greater or equal than the costs it causes.

It is straightforward to see from section 4.1 that with voluntary contributions there is no deadweight loss at all and the costs are not higher than in the other cases. Since $p_{\text {low }}<p_{C P}$ and the demand curve is downward sloping the dead weight loss with strategic pricing is less than under strong copy protection. $M$ oreover, ${ }^{-}$xed costs are also strictly lower under strategic pricing.

Although the deadweight loss is minimised under voluntary contributions, we have to verify, if this contract design creates enough returns for the principal to make production worthwhile for him. Otherwise, he would decide not to produce in the ${ }^{-}$rst place.

P roposition $4 \mathrm{~T}$ he endogenous incomplete contract design is welfare superior if $P S_{V C}=\frac{a^{2} \alpha \lambda}{2 b}, R$ 
The generated revenue $P S_{V C}$ has to cover the reservation costs $R$ to make the voluntary contributions design socially optimal.

P roposition 5 The contract with a strategically low price is welfare superior if $P S_{V C}=\frac{a^{2} \alpha \lambda}{2 b}<R \cdot \frac{d(a \mathrm{i} d)}{b}=P S_{\text {low }}$

Setting a strategically low price is socially optimal, if endogenous incomplete contracts are not pro table and $R$ is not higher than the respective revenue $P S_{\text {low }}$.

P roposition 6 Strong copy protection is welfare maximising if $P S_{V C}=\frac{a^{2} \alpha \lambda}{2 b}<$ $R$ and $P S_{\text {low }}=\frac{d\left(a_{\mathrm{i}} d\right)}{b}<R$ and $\frac{\left(\frac{a}{2}\right)^{2}}{b}, R+K$

If the voluntary contributions and the strategically low price design are not pro $^{-}$table, the reservation and compliance costs must be less than the revenue $P S_{C P}$ to make strong copy protection welfare superior.

In case none of the contract designs generates en ough revenue to exceed its respective costs, not to produce at all is socially optimal.

We have determined the conditions when each contract design is optimal for the principal and we know when each one is welfare maximising. As the - nal step of our analysis we will check now whether the di ßerent objectives are con ${ }^{\circ}$ icting.

If Proposition 3 holds and the voluntary contributions design is the most pro $^{-}$table one for $H$, then we only need to verify if P roposition 4 is ful ${ }^{-}$lled. Once the voluntary contributions revenue exceeds the reservation costs, endogenous incomplete contracts are optimal from a private and social perspective.

W hen a strategically low price is optimal as explained in Proposition 2, we have to check if Proposition 5 holds. We know that $P S_{l o w}>P S_{V C}$, but there would be a con ${ }^{\circ}$ ict between private and public interests, if endogenous incomplete contracts generate enough revenue to cover the reservation costs. The principal wants to set a strategically low price, but that is not the optimal contract design from a social point of view.

We have a similar con ${ }^{\circ}$ ict between the private and the public choice in the case of Proposition 3 when strong copy protection is most pro ${ }^{-}$table for the principal. Proposition 6 has to hold to align the interests. However, if either the revenue from voluntary contributions or from a strategically low price exceeds the reservation costs of the principal, his choice of strong copy protection maximises his pro $^{-} \mathrm{t}$ but not social welfare.

$\mathrm{G}$ enerally, con ${ }^{\circ}$ icts between the private and the public perspective arise when voluntary contributions (or the revenue from a strategically low price) cover the reservation costs of the principal, but his pro ${ }^{-} t$ is greater with another contract design (under strong copy protection). In these cases the principal chooses a contract that creates a high deadweight loss even though another contract would exceed his costs as well and would be welfare superior. From a public point of view it would then make sense to intervene by making socially e \pm cient contracts more attractive to principals. 


\subsection{Numerical Example}

O ur numerical example of the market for music uses data suggested in Romer (2002). The worldwide revenue in the industry has been roughly $\$ 40$ billion over the last decade. This has been mainly generated by the sale of albums on CDs. Singles played a minor role in the traditional music industry, but they appear to be the most popular unit online: Usually individual songs are downloaded instead of the entire album. Therefore, we use singles to model the world demand for music. The retail price for singles in the USA is ap proximately $\$ 4$ and we calculate with a marginal cost of $\$ 2$ of the CD single. A demand curve that starts with a highest valuation of $a=\$ 6$ and slopes downwards with $b=\mathrm{i} \frac{1}{5000000}$ results in an equilibrium price $p_{M}=\$ 4$ and equilibrium quantity for $C D$ music of 10 billion units (expressed in single songs). Overall, there is demand for music of 30 billion units. While this data is very rough and the estimations are not claimed to be precise, it should give a good approximate idea of the market structure.

It also explains the existence of $\mathrm{P} 2 \mathrm{P}$ - $\mid$ e sharing alongside a stagnant but by no means imploding market for traditional and online music. The demand for 20 billion songs per year that is excluded by the monopolistic price setting of the industry (to the right of $q_{M}=10 \mathrm{~B}$ and below $p_{M}=\$ 4$ ) is met by sharing. Romer (2002) assumes 18 billion tracks downloaded in 2001. More recent papers use sources from the end of 2003 with 1 billion downloads per week (Oberholzer and Strumpf (2004)), which adds up to 50 billion a year. That suggests a demand curve that is even ${ }^{\circ}$ atter to the right of $q_{M}$ (or in general).

We now apply this market demand curve to our three contract cases for digital goods (no marginal costs). That leads to a monopolistic price in the strong copy protection case of $p_{M}=\$ 3$. The condition for this is to be able to enforce the price using the threat of prosecution or implementing a secure system altogether. Early online services with strict digital rights management tried to charge high prices, but failed miserably to attract demand and copying continued. If this price level cannot be enforced by monitoring and suing ${ }^{-}$le sharing consumers, the principal has to settle for a lower price that can be enforced. We assume $p_{\text {mon }}=d+\$ 1$. Successful recent online music ventures like Apple's iT unes set a price of 99 cent. They are increasingly popular and it seems a signi ${ }^{-}$cant amount of consumers prefers high convenience music ${ }^{17}$ for this price to -le sharing music 'for free'. However, it must be mentioned that they only seem popular compared to previous online music vent ures. Their sales numbers are still tiny in contrast to -le sharing. Thus, we assume the disutility of copying $d$ to be equal to $\$ 1{ }^{18} \mathrm{~F}$ inally, based on the corresponding literature we assume the ratio of voluntary contributions $\alpha \lambda$ to be $20 \%$. This means $60 \%$ of consumers are purely self-interested and never contribute. The remaining

\footnotetext{
${ }^{17}$ Files can be saved on up to ${ }^{-}$ve di Rerent computers and unlimi ted CDs can be burned. This stands in sharp contrast to earlier online music platforms of the industry that were very restrictive.

${ }^{18}$ In reality it might be even less and $p_{\text {low }}$ might drop in the future.
} 
$40 \%$ give half of their utility of consumption as a voluntary contribution.

This results in producer surpluses of $P S_{C P}=\$ 45 B$ ( $\$ 40 B$ respectively with $\left.p_{\text {mon }}\right), P S_{\text {low }}=\$ 25 B$ and $P S_{V C}=\$ 18 B$ for the respective contract cases. That means the copyright holder could have very high compliance costs to monitor and enforce the monopolistic price and still copy protection would be most pro'table.

The compliance costs $K$ necessary to maintain strong copy protection are clearly di \pm cult to estimate. We use calculations from Eckersley (2003) for the cost of a trusted system of digital rights management. Employment of a so-called 4758 cryptographic co-processor can be regarded as a bullet proof protection. It has been developed by IBM and with some more $R \& D$ its retail price can be brought down to $\$ 100$. Each music device would be required to have one such card installed for the protection to work. If we assume that each music consumer uses only one device, we can derive the one-o ${ }^{\circledR}$ compliance costs that have to be invested (we do not consider future maintenance and upgrading costs of the system here). Under monopoly conditions demand for music is $q_{M}=15 B$. U.S. music sales usually make up one third of world sales. The U.S. population over 12 that is normally considered for U.S. consumer statistics is 200 million people. A conservative guess is that $50 \%$ of them buy music at the monopoly price. The world demand for music is then met with a reasonable estimate of an average consumption of 50 songs and 300 million music consumers worldwide (at the monop oly price). This will cause compliance costs $K=\$ 100 \$ 300 M=\$ 30 B$ to build a trusted system for music consumption.

\subsection{Dynamic Process}

A $n$ important issue to consider is whether a su \pm cient level of voluntary contributions can be maintained over time. Will contributions for the next product releases increase or decrease, when consumers see the artist received not enough or way su \pm cient support?

The question of a long-term equilibrium for voluntary contributions is analysed in public goods games. Lab experiments are conducted where subjects are confronted with a public goods situation: They can privately contribute part of or their entire endowment for the production of an e \pm cient public good, while the payo® for each subject is simply an equally big piece of the total pie. Individual self-interest is at odds with the social optimum and conventional game theory predicts that no one contributes $\{$ the strong free rider equilibrium $\{$ in sharp contrast to the Pareto-e \pm cient allocation where everybody contributes. This is known as the public goods problem. (Ledyard (1995))

The 'ndings of many standard experiments are that rates of contribution are initially around $50 \%$, but go steadily down over time. Extra features as in Cadsby and $M$ aynes (1999) improve contribution rates and can make subjects converge to the group interest equilibrium: Continuous instead of binary contributions, a money-back guarantee if the threshold is not reached, lowering the threshold and increasing the reward of contributing. A lso M enezes et al. (2001) conclude the superiority of a money-back guarantee. 
It appears that a sustainable level of contributions can be maintained when the proper design is used.

\section{Conclusion}

The paper aims to integrate the peculiarities of digital information into the social preferences framework. A model based on incomplete contracts theory is presented. It provides an alternative way to o Ber digital information goods \{ potentially more e \pm cient we conclude. $W$ ith endogenous incomplete contracts welfare is maximised and incentives to invest may be su \pm cient, while complete contracts charge a price above marginal costs and a dead weight loss is inevitable. As a policy implication this result ought to be considered for the contract design of digital cont ent. In particular, the strategically low price or the voluntary contributions design might exceed the reservation costs of the principal, but he opts for another $\left\{\right.$ welfare inferior $\left\{\right.$ contract that maximises his pro $^{-} t$. Incentives to make socially e \pm cient contracts more at tractive to principals appear to be a reasonable policy in this case.

In the broader context of the principal agent model three di ßerent contract designs are analysed: Strong copy protection, a strategically low price and voluntary contributions. We ${ }^{-}$nd that any of them can be the most pro table information goods contract for the principal. However, only the endogenous incomplete contract that encourages volunt ary contributions maximises social welfare $\{$ as long as the reservation costs of the principal are covered.

The success of endogen ous incomplete contract $s$ in the context of music likely depends on whether designs can be developed that implement mutual opportunities to reciprocate. The integration of a bonus like in Fehr, $\mathrm{K}$ lein and Schmidt (2001) makes the contract even mor e incomplete and thus leaves more room for reciprocity (from both sides). A bonus in the context of the music business could be exclusive access to concerts or backstage and special merchandising for consumers who did contribute. The implementation of reputation mechanisms is another feature that could support volunt ary contributions. It is also possible to imagine designs that remind consumers to make their volunt ary contribution in case they do enjoy the music. The freely available music ${ }^{-}$le expires after a certain time (e.g. a month) or after a certain number of times played and then the consumer can decide how much to contribute. He owns the ${ }^{-}$le if he does, while the -le disappears if he fails to. He could download it once again, but the disutility of doing that repeatedly seems to be substantial. This soft enforcement of a contribution is common for shareware software and it has the advantage that a payment decision is postponed to a time when the consumer's valuation of the experience good is clearer.

The sequence of actions could also be altered. It might be reasonable for the copyright holder to distribute a preliminary sample of the work, ask for a pre-payment, deliver the whole album (if the pre-payment was large enough) and encourage voluntary contributions. M oreover, the question of a long-term positive recipr ocity equilibrium has to be analysed, which has only been outlined 
in this paper.

A nother important question is, who the copyright holder actually is. Is it the record label like in the traditional music industry or the artist? The implications on the potential fair behaviour of agents ( an impersonal market trade between consumer and company or a social personal exchange between consumers and their artists) and also on the de nition of the reservation costs are signi ${ }^{-}$cant. $R$ elated research on the e \pm cient ownership structure in the music industry like Clemons and Lang (2003) and R egner (2003) points out that label ownership of music copyright becomes less likely in the digital age. It also matters whether the artist is already "rich and famous" or if he or she is just starting. Voluntary contributions are probably more likely to be given to newcomer artists than to millionaire pop stars based on behaviour motivated by inequity aversion. ${ }^{19}$

Eventually, it will be up to the market forces to deter mine for which principal strong copy protection, strategically low pricing or the voluntary contributions design is best suited and when.

The paper opens up an interesting ${ }^{-}$eld for future research. $\mathrm{M}_{\text {odi }}{ }^{-}$ed experiments to test for social preferences in digital age contexts would be a logical next step. Moreover, it needs to be investigated in more detail when endogenous incomplete contracts for information goods are successful and how they have to be designed.

\footnotetext{
${ }^{19}$ However, one example of an artist that has chosen a voluntary contributions design is clearly of the "rich and famous" type: George Michael. See BBC (2004).
} 


\section{R eferences}

[1] ARROW, K. ( 1962). "E conomic Welfare and the Allocation of R esources for Invention", in: Nelson, R. ed., "T he R ate of Inventive Activity: Economic and Social Factors", Princet on University Press, P rinceton

[2] BBC (2004) online at (last accessed 18.07.2004): http:// news.bbc.co.uk/2/ hi/entertainment/ 3499534.stm

[3] BESE N, S. M ., and S. N. KIRBY (1989): "Private Copying, A ppropriability, and Optimal Copying Royalties," J ournal of Law \& E conomics, 32, 255280.

[4] BOLTON, G. E., and A. OCKENFELS (2000): "ERC: A Theory of Equity, Reciprocity, and Competition," A merican E conomic Review, 90, 166-193.

[5] CADSBY , C. B ., and E. M AY NE S (1999): "Voluntary Provision of Threshold Public G oods with C ontinu ous C ontributions: Experimental Evidence," J ournal of Public Economics, 71, 53-73.

[6] CAMERER, C. (2003): "B ehavioral Game Theory: Experiments in Strategic Interaction", Princeton University Press, P rinceton

[7] CHARNESS, G., and M. RABIN (2002): "Understanding Social Preferences with Simple Tests," Quarterly J ournal of Economics, 117, 817-869.

[8] CLEM ONS, E., and M. LANG (2003): "The Decoupling of Value Creation from Revenue: A Strategic A nalysis of the Markets for Pure Information Goods" J ournal of Informati on Technology \& M anagement, 4, $259\{287$.

[9] DUfWEnBerg, M., and G. KIRChSTEIGER (2004): "A Theory of Sequential Reciprocity," Games and E conomic Behavior, 47, 268-298.

[10] ECKERSLEY, P. (2003): "The Economic Evaluation of A lternatives to Digital Copyright," University of M elbourne working paper.

[11] FAHR, R., and B. IRLENBUSCH (2000): "Fairness as a Constraint on Trust in Reciprocity: Earned Property Rights in a Reciprocal Exchange Experiment," Economics Letters, 66, 275-282.

[12] FEHR, E., S. G ÄCHTER, and G. KIRCHSTEIGER (1997): "Reciprocity as a Contract Enforcement Device: Experimental Evidence," Econometrica, 65, 833-860.

[13] FEHR, E., A. KLEIN, and K. M. SCHMIDT (2001): "Fairness, Incentives and Contractual Incompleteness," U niversity of M unich working paper

[14] FEHR, E., and K. M. SCHMIDT (1999): "A Theory of Fairness, Competition, and Cooperation," Quarterly J ournal of Economics, 114, 817-868. 
[15] (2000): "Fairness, Incentives, and Contractual Choices," European E conomic Review, 44, 1057-1068.

[16] GeAnAKOPLOS, J., D. PeARCE, and E. STACCHETTI (1989): "Psychological Games and Sequential R ationality," $G$ ames and $E$ conomic B ehavi or, $1,60-79$

[17] HARMON, A. (2003): "Suit Settled For Students Downloading Music Online", online at (last accessed 13.05.2003): http:/ / www.nytimes.com/ 2003/ 05/ 02/ national/ 02ST UD.html?th.

[18] LEDYARD, J . (1995). " Public G oods: A Survey of Experimental Research", in " $T$ he $\mathrm{H}$ andbook of Experimental E conomics", edited by J ohn $\mathrm{K}$ agel and A lvin R oth, 111-194, Princet on, Princeton University Press

[19] LANDES, W. M., and R. A. POSNER (1989): "An Economic-A nalysis of Copyright Law," J ournal of Legal Studies, 18, 325-363.

[20] LERNER, J., and J. TIROLE (2002): "Some Simple Economics of O pen Source," J ournal of Industrial Economics, 50, 197-234.

[21] LIE BO WITZ, S. J . (1985): "C opying and Indirect A ppropriability - P hot ocopying of J ournals," J ournal of Political E conomy, 93, 945-957.

[22] MACHO-STADLER, I., and D. PEREZ-CASTRILLO (2001): "A n Introduction to the Economics of Information", Oxford University Press, Oxford.

[23] Menezes, F. M., P. K. MONTEIRO, and A. TEMIMI (2001): "Private Provision of Discrete Public Goods with Incomplete Information," J ournal of Mathematical E conomics, 35, 493-514.

[24] OBERHOLZER, F., and K. STRUMPF (2004): "T he E Rect of F ile Sharing on Record Sales: An Empiric A nalysis," mimeo

[25] New York Times (2003): "Court Says Verizon Must Identify Downloaders", online at (last accessed 13.05.2003): http:/ / query.nyt imes.com/ gst/ abstract.html? res=F 00F 14F 93C 590C 768E D D A D 0894 D B 404482

[26] PLA NT , A . (1934): "T he E conomic A spects of Copyright in B ooks," E conomica, 1, 167-195.

[27] QUAH, D. (2003): "Digital Goods and the New Economy," Centre for Economic Performance discussion paper 563

[28] REGNER, T . (2003): "Innovation of M usic", in "The E conomics of Copyright: Developments in Research and A nalysis", edited by Richard Watt, chapter 6, pages 104 to 117, Cheltenham, Edward Elgar Publishing.

[29] RE GNER, T. (2004): "Why Voluntary Contributions? Google Answers!", mimeo 
[30] RABIN, M. (1993): "Incorporating Fairness into Game-Theory and Economics," A merican E conomic Review, 83, 1281-1302.

[31] RICHTEL, M. (2003): "Entertainment Industry Loses in Net Case", online at (last accessed 13.05.2003): http:/ / www.nytimes.com/ 2003/ 04/ 26/ technology/ 26M USI.html?th

[32] ROMER, P. (2002): "W hen Should We U se Intellectual Property Rights?," American Economic Review, 92, 213-216.

[33] SHAPIRO, C., and H. R. VARIAN (1999). "Information Rules", Harvard Business School Press, B oston.

[34] SMITH, A. (1759, reprinted 1976). "The Theory of M oral Sentiments" in: Liberty Classics, edited by D. D. R aphael and A. L. M actie, Liberty Press, Indianapolis.

[35] SMITH, V. L. (1962): "An Experimental Study of Competitive Market Behaviour," J ournal of Political Economy, 70, 111-137.

[36] SMITH, V. L. (1998): "The T wo Faces of Adam Smith," Southern Economic J ournal, 65, 2-19.

[37] SORKIN, A. R. (2003): " Software Bullet Is Sought to Kill Musical Piracy", online at (last accessed 13.05.2003): http:// www.nytimes.com/ 2003/ 05/ 04/ business/ 04M U SI. html? pagewanted=1\& th

[38] TAKEYAMA, L. N. (1994a): "The Shareware Industry: Some Stylized Facts and Estimates of Rates of Return," Economic Innov. New Techn., 3, 161-174.

[39] TAKEYAMA, L. N. (1994b): "The Welfare Implications of Unauthorized Reproduction of Intellectual P roperty in the Presence of Demand N etwork Externalities," J ournal of Industrial E conomics, 42, 155-166.

[40] TORVA LDS, L. (1999). "W hat Makes Hackers Tick? A.k.a. Linus's Law" in Himanen, P. "T he Hacker Ethic", V intage, London .

[41] VARIA N, H. R . (2000): "Buying, Sharing and R enting Information G oods," J ournal of Industrial E conomics, 48, 473-488.

[42] VARIA N, H. R. (2004): "The Social Cost of Sharing", mimeo

[43] WATT, R. (1999). "Copyright and Economic Theory: Friends or Foes?", Cheltenham, Edward Elgar Publishing.

[44] Wired (2003). "Under Cover" and "Dirty Dozen", February 2003 issue

[45] Y OON, K . (2002): "The O ptimal Level of Copyright Protection," Information E conomics and Policy, 14, 327-348. 